\title{
Argumento (1973-1974) e Cadernos de Opinião (1975-1980): marcos de uma passagem
}

\author{
Jeferson Candido ${ }^{1}$ \\ Universidade Federal de Santa Catarina - UFSC, Florianópolis, Santa Catarina, Brasil
}

Resumo: O artigo revisita brevemente a revista Argumento (1973-1974) para deter-se, em seguida, na trajetória e características da revista Cadernos de Opinião (1975-1980), também chamada Ensaios de Opinião entre os números $3(2+1)$ e $11(9+2)$. Tomando as duas revistas em série, tendo em vista a origem de ambas, e observando as mudanças ocorridas no trabalho intelectual a partir da Reforma Universitária promovida pela ditadura brasileira em 1968, a comparação entre as publicações indica que, à medida que os "novos" intelectuais, ou, melhor, o paradigma por eles representado, assume o protagonismo (inclusive político), cabe aos anteriores o lugar da homenagem.

Palavras-chave: Década de 1970; Ditadura; Periodismo; Intelectual.

Title: Argumento (1973-1974) and Cadernos de Opinião (1975-1980): milestones of a passage

Abstract: The article briefly revisits the magazine Argumento (1973-1974) to then stop at the trajectory and characteristics of the magazine Cadernos de Opinião (1975-1980), also called Ensaios de Opinião between the numbers $3(2+1)$ and $11(9+2)$. Taking the two magazines in series, considering the origin of both, and observing the changes that occurred in the intellectual work since the University Reform promoted by the Brazilian dictatorship in 1968, the comparison between the publications indicates that, as the "new" ones intellectuals, or, better, the paradigm they represent, assumes the protagonism (including political), it is up to the previous ones the place of the homage.

Keywords: 1970s; Dictatorship; Periodism; Intellectual.

\section{Argumento iluminista}

Em seu depoimento por ocasião do aniversário de 80 anos de Fernando Henrique Cardoso, Antonio Candido (2011) discorre sobre um único fato, "um fato menor, mas digno de registro: a sua participação essencial [de FHC] no esforço de um grupo de intelectuais na revista Argumento". 2 Segundo Candido, pouco tempo antes, durante o governo Médici, ele, Fernando Henrique e Arnaldo Pedroso d'Horta haviam pensado em criar uma revista "que pudesse, na medida do possível, furar a carapaça repressiva e manter o pensamento livre

\footnotetext{
${ }^{1}$ Doutor em Literatura pela Universidade Federal de Santa Catarina (UFSC). Pesquisador do Núcleo de Estudos Literários \& Culturais (NELIC-UFSC). Orcid: http://orcid.org/0000-0003-0874-6512 E-mail: jcandido@outlook.com

${ }^{2}$ Ver também CANDIDO (2003).
} 
com tonalidade crítica". O projeto não deu certo, "mas pouco depois Fernando Gasparian sugeriu o mesmo e assegurou as condições materiais para a sua realização".

Nascido em São Paulo, numa família que se fez industrial a partir da década de 1930 (um dado bastante relevante), Fernando Gasparian retornara ao Brasil em 1972, depois de um período de autoexílio com a família na Inglaterra, devido a sua proximidade com o governo deposto em 1964. Foi nesse mesmo período que Gasparian teve a ideia de criar uma publicação de oposição ao regime, que resultaria, afinal, no semanário Opinião, lançado em outubro de 1972. Em 1973 adquiriria, de Ênio Silveira, a editora Paz e Terra.

Com a criação de uma revista, além de atrair seus amigos intelectuais afastados do Opinião "pela censura ou pelo que ele considerava sectarismo crescente do jornal", segundo Kucinski (2003, p. 329), o empresário e agora editor também retomava sua proposta original, preterida no processo de criação do semanário: uma publicação que funcionasse como um veículo de ideias, escrita por intelectuais. Nascia assim Argumento - Revista mensal de cultura. Publicada pela editora Paz e Terra, a revista foi lançada em outubro de 1973. Teria vida curta e fama longa.

Como no Opinião, o projeto gráfico da nova publicação coube a Elifas Andreato. Com belas capas e um formato singular, quase quadrado, média de 150 páginas com textos diagramados em duas colunas, rica iconografia - ilustrações, reproduções, fotografias - e impressa em papel de qualidade, Argumento se destacava já, como bem aponta Kucinski (2003, p. 329), "como um objeto cultural, mais do que uma simples coleção de textos, retomando, na metade do tamanho, a experiência gráfica da Senhor".

Para além de seu aspecto de "objeto cultural", o grande trunfo da revista era seu conselho consultivo integrado por "intelectuais de peso" (palavras de Candido): Érico Veríssimo, Florestan Fernandes, Paulo Duarte, Sérgio Buarque de Holanda, Simão Mathias, Alceu Amoroso Lima, Hélio Jaguaribe, Aníbal Pinto, Octavio Paz, Torcuato di Tella, Albert Hirschman, Brian Van Arkadie, Dudley Sears e Alain Touraine.

A comissão de redação contava com Anatol Rosenfeld, Antonio Candido, Celso Furtado, Fernando Henrique Cardoso, Francisco Weffort, Leôncio Martins Rodrigues (este apenas no primeiro número), Luciano Martins e Paulo Emilio Sales Gomes. Maria Hermínia Tavares de Almeida era a secretária e Eduardo Graeff o editor de texto. O diretor responsável era o então candidato a vice-presidente da República (na chapa simbólica encabeçada por Ulysses Guimarães) pelo MDB, Barbosa Lima Sobrinho.

Não obstante o grande número de nomes elencados no conselho consultivo e na comissão de redação (este "vário na idade e na preocupação"), o núcleo responsável pela revista era reduzido. Candido (2011) conta que, embora a comissão fosse formada por gente do Rio e São Paulo, as reuniões ocorriam em São Paulo, onde era produzida a revista: "todas as semanas nos reuníamos Fernando Henrique, Paulo Emilio Sales Gomes, eu e, até o número 3, quando infelizmente morreu, Anatol Rosenfeld, além de Maria Hermínia Tavares de Almeida [...]. Gasparian era presença ativa, depois de ter sido o ideador". Também Ángel Rama participou de algumas das reuniões da revista no final do ano, quando esteve em São 
Paulo a convite de Candido para ministrar dois seminários na USP. ${ }^{3}$

O editorial de apresentação da revista - escrito por Paulo Emilio - se assumia como um breve manifesto, conforme sua incisiva última frase:

\begin{abstract}
A natureza social tem horror ao vácuo cultural e tende a preenchê-lo de uma forma ou de outra. Uma das formas de fazê-lo é utilizando a dependência, a acomodação, o arrivismo.

A nossa pretende ser a outra forma, a que se definirá no percurso de nosso grupo. Este é vário na idade e na preocupação, mas se unifica no entendimento em criar um veículo novo para o que há de vivo, válido e independente na circunstância cultural brasileira; e um ponto de encontro com o pensamento de outras terras, notadamente as do continente.

Os obstáculos que eventualmente encontrarmos e os estímulos que recebermos serão igualmente indicativos da utilidade de nossa função. Muito intelectual brasileiro foi arrancado de seu mundo e é preciso que encontre um terreno onde possa novamente se enraizar. A limitação de nosso campo poderá ainda ser restringida, mas sempre haverá um papel a ser cumprido pelo intelectual que resolva sair da perplexidade e se recuse a cair no desespero.

Nascemos sem ilusões e não está em nosso programa nutri-las. A independência custa caro e não encoraja as subvenções. Não temos propriamente o que vender mas nos achamos em condições de propor um esforço de lucidez. Esta não é artigo de luxo ou de consumo fácil mas em qualquer tempo é alimento indispensável pelo menos para alguns. Sua raridade é, aliás, sempre provisória; tudo que a lucidez revela tende a se transformar em óbvio.

Contra fato há argumento. ([EDITORIAL], 1973, p. 1) ${ }^{4}$
\end{abstract}

A nova "revista mensal de cultura" obteve sucesso - político, cultural e comercial imediato: a tiragem de 25.500 exemplares dos dois primeiros números foi ampliada para 45.500 nos números 3 e $4 .{ }^{5}$ Mas assim como o sucesso, a reação também foi imediata.

Duas semanas após o lançamento a Polícia Federal recolhia os exemplares que ainda estavam nas bancas sob a alegação de que Argumento era uma revista "clandestina", uma vez que não havia sido registrada na Divisão de Censura de Diversões Públicas. Segundo reportagem do Jornal do Brasil, em Brasília comentava-se que a revista dificilmente voltaria a circular, mesmo com o pedido de registro, pois o processo de liberação ou rejeição podia ser demorado, dependendo da conveniência ou oportunidade da publicação (DPF DIZ QUE TIROU DAS BANCAS..., 1973, p. 17). O registro seria concedido, contudo, dias depois.

No final de janeiro, porém, o sucesso, que fora imediato, torna-se também fulminante. A Polícia Federal ordena que a revista seja submetida à censura prévia, com 10 dias de antecedência da data de publicação, a partir do número 4 . O número, entretanto, já havia sido impresso. Barbosa Lima Sobrinho escreve ao Ministro da Justiça, Armando Falcão, pedindo a liberação da revista, com a justificativa de que o número fora impresso conforme

\footnotetext{
3 Segundo VASCONCELOS (2001, p. 34), Rama ficou encantado com a publicação e cogitou a possibilidade de fazer uma revista latino-americana na esteira de Argumento.

${ }^{4} \mathrm{O}$ editorial (sem título) precede mesmo o expediente da revista.

${ }^{5}$ E ainda que sem ter "propriamente o que vender", chegou a atrair mesmo anunciantes: Datamec, Grupo Financeiro Novo Rio, Alitália, Arredamento Móveis e CCE (eletrônicos), além da óbvia publicidade da Paz e Terra e, também, da editora Civilização Brasileira.
} 
as normas então vigentes, e acusando o prejuízo acarretado pela apreensão (STF ADVERTE QUE A CENSURA..., 1975, p. 14). ${ }^{6}$

Em abril, ainda na tentativa de liberar a revista, Fernando Henrique Cardoso relata que, pela primeira vez na vida, tentou valer-se da rede de conexões de sua família. Junto com Antonio Candido, procurou o general reformado Oswaldo Cordeiro de Farias, que Ihes conseguiu uma entrevista com o general Golbery, chefe da Casa Civil. Golbery, por sua vez, os mandou à busca do Ministro da Justiça, Armando Falcão, que os recebeu rispidamente e não tomou providência alguma (CARDOSO, 2015).

A última saída buscada por Gasparian foi repetir o que já tentara com o Opinião em 1973: um mandado de segurança no Tribunal Federal de Recursos contra o Departamento de Polícia Federal, a fim de liberar os 45 mil exemplares do número 4 de Argumento (EDITORA RECORRE AO TFR..., 1974, p. 2). Dessa vez, entretanto, o TFR declarou-se incompetente para julgar a matéria, já que a apreensão da revista fora determinada por ato do Presidente da República, passível de julgamento apenas pelo Supremo Tribunal Federal. O TFR lembrava ainda o ocorrido no ano anterior, quando o mandado concedido à editora Inúbia, responsável por Opinião, teve como resultado um despacho da presidência reafirmando a censura prévia do semanário (STF JULGARÁ APREENSÃO..., 1974, p. 20).

No final do ano, respondendo ao pedido de informações do STF para a instrução do julgamento, o governo aponta o Al-5 como o documento legal a sustentar a censura prévia imposta à Argumento. Segundo parecer do Ministério da Justiça, a revista estava "sujeita às normas constitucionais autorizadoras de medidas coercitivas, idênticas às facultadas no Estado de Sítio, desde que adotadas aquelas em defesa da revolução" (GOVERNO RECORRE A Al-5..., 1974, p. 7). Finalmente, em agosto de 1975, como afirma já no título a reportagem do Jornal do Brasil - que faz um resumo do caso desde a apreensão da revista -, o "STF adverte que a censura tem poder de exceção" (1975, p. 14). Sem aceitar o fato, o grupo responsável pela revista preferiu encerrá-la (CANDIDO, 2011).

\section{Os Cadernos + os Ensaios de Opinião}

Mas a insistência de Fernando Gasparian em fazer publicações contrárias à ditadura, convenhamos, era notável. Com Opinião sob censura prévia desde janeiro de 1973, e antes mesmo do julgamento final do mandado de Argumento, ele coloca nas bancas outra revista: Cadernos de Opinião. A associação entre a revista e o semanário é imediata, sendo mesmo realçada pelo uso do logotipo de Opinião em seu título.

Estampando na capa o nome dos colaboradores, com grande destaque para o de Celso

\footnotetext{
${ }^{6}$ É preciso atentar na data da reportagem: o episódio é narrado apenas quando do julgamento final no STF do mandado de segurança impetrado pela editora Paz e Terra, já que a divulgação da apreensão de Argumento foi censurada, conforme ordem de 21 de janeiro de 1974: "De ordem superior, fica proibida a divulgação, através dos meios de comunicação social, de noticiário, referência, transcrição, comentário, matéria paga, etc, sobre a Revista Argumento, da Editora Paz e Terra. (Gen. Antonio Bandeira)" (OS DOCUMENTOS DA CENSURA, 1978, p. 5).
} 
Furtado (acompanhado do título de seu ensaio "O capitalismo pós-nacional"), os Cadernos também publicados pela editora Inúbia - são lançados em 9 de junho de 1975 no Teatro Casa Grande, no Rio, com uma mesa redonda mediada pelo senador Roberto Saturnino Braga na qual, além do próprio Furtado, comparecia também Fernando Henrique Cardoso, que lançava seu livro Autoritarismo e democratização, publicado pela Paz e Terra. Contrariamente ao que dissemos de Argumento, podemos dizer que os Cadernos teriam vida longa, ainda que irregular, e fama curta.

A começar pelo aspecto gráfico, os Cadernos em nada lembravam a prestigiada revista anterior: capa sóbria em papel couchê, 110 páginas sem nenhuma ilustração e impressa em papel jornal, aspecto que melhoraria um pouco a partir do segundo número. Outra disparidade com relação à Argumento marca ainda mais fortemente os Cadernos: se aquela trazia um numeroso elenco de notáveis em seu conselho consultivo, comissão de redação e direção, esta não trazia um único nome sequer além daqueles dos colaboradores. Também não sabemos o que pretende a nova revista, já que não há editorial ou apresentação.

Apesar do mistério, não havia mistério algum: o "diretor/editor oculto" dos Cadernos era, claro, Fernando Gasparian, como seria obrigado a reconhecer mais tarde (obrigado mesmo, pela justiça militar). A ausência de corpo editorial era "estratégica": sem redação e sem diretor responsável, os Cadernos de Opinião não eram uma revista, mas uma coleção de livros publicados em série. Não precisavam, pois, ser registrados no Departamento de Censura de Diversões Públicas da Polícia Federal, o que os livrava de uma provável censura prévia (DIRETOR EXPLICA PUBLICAÇÃO, 1975, p. 6). ${ }^{7}$

Assim, resultado da estratégia ou do descuido da polícia, o primeiro número circulou normalmente. O segundo - que trazia logo abaixo do índice a informação "Este livro é uma publicação da Editora Inúbia" - seguia também circulando três semanas depois de lançado, quando na manhã de 6 de agosto agentes da Polícia Federal apreenderam em diversas bancas do Rio cerca de 300 exemplares, sob justificativa de uma ordem emitida pelo Ministério da Justiça. De acordo com o Jornal do Brasil, os diretores da publicação - em provável referência a Gasparian e Eurico Amado, seu sócio na editora - afirmavam desconhecer os motivos da apreensão, embora admitissem que ela pudesse ser devida à publicação, no número apreendido, de uma palestra do Arcebispo de Olinda e Recife, Dom Hélder Câmara (CADERNOS DE OPINIÃO É APREENDIDO, 1975, p. 7). ${ }^{8}$

De fato. Talvez empolgado com a livre circulação do primeiro número, crente de que a estratégia do "livro" funcionara, Gasparian acabou por cometer um pecado grave aos olhos da ditadura: toda e qualquer menção a Dom Hélder Câmara estava rigorosamente proibida nos "meios de comunicação social". E não bastasse essa proibição, a palestra do Arcebispo de Olinda e Recife, pronunciada na Universidade de Chicago em outubro de 1974, tinha por

\footnotetext{
${ }^{7}$ A publicação da revista sem a anuência da censura faz com que sua baixa qualidade gráfica revele-se também estratégica: implicando diretamente os custos, reduz o prejuízo a ser causado por uma possível apreensão.

8 A reportagem informa que os 300 exemplares recolhidos representavam um por cento da publicação, o que nos dá, portanto, uma tiragem bastante significativa, de 30 mil exemplares.
} 
título uma "sugestiva", diríamos, pergunta: "O que faria S. Tomás de Aquino diante de Karl Marx?". Em sua fala, Dom Hélder parte da leitura empreendida por Tomás de Aquino da obra de Aristóteles, um autor à época proscrito pela Igreja, para tecer relações entre os pensamentos cristão e marxista, concluindo pela necessidade de diálogo entre a Igreja e a obra de Marx.

No dia seguinte à apreensão, segundo Alberto Dines, Gasparian foi ao Ministério da Justiça para saber dos motivos, sendo informado de que desconheciam tal ordem. Foi então à Polícia Federal, que também negou a autoria da ação. Sua conclusão era de que tudo não passava de um equívoco (DINES, 1975b, p. 6). Dines discordava dessa conclusão, e o título de sua nota - "A indefinição como tática" - mostrou-se certeiro.

A Polícia Federal já havia enviado em 28 de julho um ofício ao ministro Armando Falcão, no qual relatava que a "revista mensal" Cadernos de Opinião descumprira "ordem de proibição específica determinada por Vossa Excelência", citando a publicação da palestra de Dom Hélder. A partir daí, seguia o ofício: “outros artigos publicados na mesma edição caracterizam a tendenciosidade dos responsáveis pela revista [e] apresentam conotações que os identificam com uma autêntica campanha psicológica adversa". Por fim, relatava que a revista não estava registrada na Divisão de Censura de Diversões Públicas nem apontava os nomes do autor e editor responsáveis pela publicação (DOCUMENTOS DA APREENSÃO..., 1979 , p. 4-5). Diante do ofício, Falcão solicitara um parecer ao consultor jurídico substituto do Ministério da Justiça, Hélio Fonseca.

Datado de 30 de julho, o parecer é um documento típico da obtusidade e violência instalada no poder e ao redor dele. O "consultor jurídico substituto" afirma que Cadernos de Opinião é "um verdadeiro repto ao governo", que "a tônica de seus colaboradores é a propaganda subversiva" e que "urge colocar um paradeiro neste abuso". Pede a aplicação do Al-5 e recomenda "medidas enérgicas por parte da Polícia Federal", medidas essas que, "além de imporem castigo à desobediência, traduzirão um claro aviso a todos os grupos que fazem investidas no mesmo sentido". Propõe a apreensão da revista e afirma que será instaurado um inquérito policial "para a apuração de propaganda subversiva, a ser oportunamente submetido à Justiça Militar". Para o inquérito, sugere "rigorosa investigação a respeito da editora Inúbia", "tendente a promover sua extinção", a "investigação do grau de comprometimento da Cia. Editora Fon-Fon e Seleta [responsável pela impressão] com o grupo responsável pelos Cadernos, para o estudo de medidas repressivas" e, por fim, "a avaliação dos custos dos Cadernos, bem como a respectiva fonte de receitas, a fim de comprovar apoio financeiro por fontes externas" (DOCUMENTOS DA APREENSÃO..., 1979, p. 4-5). ${ }^{9}$

Estratégia contra estratégia. Se nos embates anteriores com a censura Gasparian tomara a frente, impetrando mandados de segurança, desta vez os papéis se invertiam. Intimado a depor em 25 de agosto, responderia a três horas e meia de interrogatório na Polícia Federal sobre o segundo número dos Cadernos (e ainda sobre seu passado político e

\footnotetext{
${ }^{9}$ Ainda quando dos primeiros movimentos do inquérito Alberto Dines (1975a, p. 10) apresentou um resumo desse parecer em sua coluna.
} 
sua filiação ao $\mathrm{MDB}$ ), sendo advertido também de que os originais do terceiro número teriam que ser submetidos à censura, apesar de seus protestos contra a decisão, "que constituiria fato inédito no país, onde os livros não são objeto de censura prévia" (DIRETOR EXPLICA PUBLICAÇÃO, 1975, p. 6). Mas, como sublinhava Alberto Dines (1975a, p. 10), "estava decretado: Cadernos de Opinião não é livro, é revista". Um "meio de comunicação social", portanto.

O inquérito instaurado pela Polícia Federal foi distribuído à 1a Auditoria da Marinha, onde Gasparian acabou denunciado por propaganda subversiva. A denúncia é rejeitada em abril de 1976, mas a promotoria recorre ao Superior Tribunal Militar. Apenas em janeiro de 1978 o caso seria definitivamente encerrado, com o STM confirmando a decisão da primeira instância: a conferência de Dom Hélder transcrita nos Cadernos número 2 não era “atentatória à segurança nacional” (INQUÉRITO VAI À AUDITORIA, 1975, p. 4). ${ }^{10}$

Denunciado por propaganda subversiva e obrigado a registrar e submeter sua "coleção de livros" à censura prévia, Gasparian resolve suspendê-la. E iniciar uma nova, ainda em 1975: a Coleção Ensaios de Opinião. Contendo mais ilustrações, com fotografias pessimamente reproduzidas, o primeiro "livro" da nova coleção é idêntico aos anteriores, mesmo na tipologia do título, trocando apenas "cadernos" por "ensaios". O detalhe é que, além de repetir descaradamente a "estratégia" anterior ${ }^{11}$, os Ensaios traziam uma estranha numeração: seu primeiro número não era o 1 , mas o 2+1, leia-se: número 3 . Dando destaque ao nome de Getúlio Vargas na capa, o primeiro (o terceiro) número dos Ensaios dedica-Ihe um dossiê que ocupa metade das 110 páginas do volume, com a publicação, inclusive, de alguns de seus discursos.

Tudo indica, porém, que esse número teve uma circulação bastante restrita. Não encontramos informações de que tenha sido apreendido, tampouco referências ou comentários acerca de seu lançamento, ocorrido, presumimos, entre setembro e dezembro, ou mesmo alguma repercussão posterior. ${ }^{12} \mathrm{~A}$ hipótese mais provável é que Gasparian tenha se valido de mais uma "estratégia": um tal cuidado diante da possibilidade de apreensão que, ao final, sem divulgação e sem lançamento, o número acabaria por passar despercebido não só da polícia, mas também do público. ${ }^{13}$ Sabemos, por outro lado, que um dos textos presentes em Ensaios de Opinião 2+1, "Amado, respeitoso, respeitável”, polêmico ensaio de Walnice Nogueira Galvão sobre Teresa Batista cansada de guerra, de Jorge Amado, foi republicado, pouco tempo depois, na edição de 23 de fevereiro de 1976 do Jornal de

\footnotetext{
${ }^{10}$ Ver também REJEITADA DENÚNCIA CONTRA... (1976, p. 12) e STM NÃO ACHA SUBVERSÃO... (1978, p. 18).

${ }^{11}$ Valendo-se também de uma mais efetiva - a impressão em outra cidade -, conforme indica a última página: "Este livro foi impresso na Cia Lithographica Ypiranga", de São Paulo.

12 Por se tratar de um "livro", consta apenas o ano da impressão - 1975 - na segunda página. Nesse mesmo período, contudo, um anúncio em Opinião n. 151 (26 set. 1975) informa: "Cadernos de Opinião n. 1 volta às bancas". $O$ anúncio não se repetiu.

${ }^{13}$ Essa foi a estratégia utilizada por Gasparian em 1977 quando da publicação, pela Paz e Terra, do livro de Jean Ziegler, A Suíça acima de qualquer suspeita, o que acabou por encalhar a edição (GASPARIAN, 2005).
} 
Debates, do Rio de Janeiro, o que corrobora sua limitada circulação anterior.

Há, então, uma longa pausa na publicação de Ensaios de Opinião. Não podemos negligenciar o aspecto financeiro que envolve essa série de publicações e, nesse mesmo período, Opinião tem novamente sua redação esvaziada, não apenas por conta da censura desanimadora, mas, principalmente, pelos salários defasados. É ao semanário, afinal sua principal publicação, que Gasparian dará prioridade.

Somente em junho de 1977 - dois meses depois, portanto, do fim de Opinião (em abril de 1977) - a revista voltaria às bancas, com o "vol. 4" da Coleção Ensaios de Opinião (FERREIRA, 1977, p. 8). Ensaios se assume cada vez mais graficamente como uma revista, com grande quantidade de ilustrações, mas continua sendo oficialmente um livro, como "comprova" agora uma ficha catalográfica: CDD - 808.84, CDU - 82-4(082). A coleção não teria, porém, nenhum outro número publicado em 1977.

O número seguinte $(2+3)$, embora datado de 1977 , seria lançado apenas em fevereiro de 1978. A capa destaca o dossiê dedicado às comunicações apresentadas em dois simpósios da 29a Reunião Anual da Sociedade Brasileira para o Progresso da Ciência (SBPC), realizada em julho de 1977 em São Paulo, que ocupa metade do volume. Mas o dado mais relevante é que a revista (ou livro) apresenta, pela primeira vez, editores: Fernando Gasparian e Florestan Fernandes Júnior.

A partir daqui, ainda que de maneira um tanto irregular (e formalmente como livros), os Ensaios de Opinião teriam publicação contínua pela editora Paz e Terra. Depois de uma breve pausa, em junho é lançado o número 2+4, com dossiê dedicado a Paulo Emilio Sales Gomes e tendo como editores Fernando Gasparian e Jean-Claude Bernardet. Os números $2+5$ e 2+6, lançados em julho e agosto, trazem como editores Fernando Gasparian, Theo Santiago e Dalva Gasparian (esposa da Fernando). No número 2+7, o último de 1978 e lançado em novembro, no entanto, a revista volta a não apresentar editor ou editores. Mas apresenta, por outro lado, um "conselho de colaboradores", na verdade - como enfatiza o nome do semanário acima da lista -, o mesmo de Opinião: Alceu Amoroso Lima, Antônio Callado, Antonio Candido, Celso Furtado, Fernando Gasparian, Fernando Henrique Cardoso, Francisco de Oliveira, Francisco Weffort, Luciano Martins, Millôr Fernandes, Paul Singer e Ruth Cardoso (esta última substituindo Paulo Emilio, morto em setembro de 1977).

Com essa configuração seriam publicados, já livres do Al-5, os números $2+8$ em abril que reproduz artigo de Ralph Della Cava sobre a tortura no Brasil, acompanhado de sua polêmica com Lincoln Gordon, e o 8o capítulo do livro de Marcos de Castro, Dom Hélder Câmara - e 2+9 em junho - que dedica mais da metade do volume a um dossiê sobre a questão agrária. E aqui se encerram os Ensaios de Opinião: no mês seguinte é lançado o número 12 de Cadernos de Opinião - "Revista cultural brasileira, publicada mensalmente" -, em tudo semelhante aos "livros" anteriores. Ou em quase tudo, posto que os detalhes, de modo geral irrelevantes, ajudam a compor aqui um retrato de época. Assim, no lugar da ficha catalográfica, encontramos, na primeira página, seu número, mês e ano. Temos informações sobre a distribuição em bancas e livrarias e valor de assinatura. Os nomes "de peso" permanecem no "conselho editorial". E como "diretor responsável", Fernando Gasparian. 
Os Cadernos podem também assumir um programa, ou, estando já no 120 número, explicitá-lo ao leitor. Seu primeiro (e único) editorial não poderia começar por outra afirmação: "A partir deste número readquirimos nossa identidade originária". E voltando a 1975 esclarece a origem da revista e seu sobrenome:

\begin{abstract}
Matérias da maior importância e que jamais poderiam ser alvo da fúria censória, em qualquer país onde houvesse o mínimo de respeito pela inteligência e pela cultura, eram sumariamente eliminadas das páginas de Opinião. Por outro lado, chegavam ao nosso jornal ensaios, estudos, trabalhos que, apesar de sua alta qualidade intelectual, não eram jornalísticos. Em virtude mesmo de sua densidade cultural, ultrapassavam o sentido menos permanente, digamos assim, característico das matérias destinadas à editoração em jornal. A umas e outras cumpria, porém, salvá-las, ou porque representassem abordagem de temas palpitantes, ou porque constituíssem decisivas contribuições ao pensamento brasileiro. Com esse duplo propósito concebemos, então, o lançamento de Cadernos de Opinião. ([EDITORIAL], 1979 , p. 3, grifo do original)
\end{abstract}

São explicadas as estratégias e percalços que acompanhamos até aqui: a adoção do formato de livro, a mudança de nome e a estranha numeração ("no propósito de não conceder um mínimo à censura"), a apreensão do número 2 e o longo processo sofrido, de caráter punitivo e "assentado no princípio medieval de ato de poder revestido de sentido exemplar", como comprovam os documentos reproduzidos nas páginas seguintes. Ao final, destacando a coerência e apontando para o futuro da revista, afirma: "continuamos mantendo em relação às matérias que divulgamos a mesma orientação de há quatro anos. [A verdade], que é a arma que os poderes autocráticos mais temem, continuará a ser dita nestas páginas, abertas à intellgentzia brasileira e à universal".

Mas as páginas dos Cadernos de Opinião não continuariam abertas por muito tempo mais. O número 13 (ago./set. 1979) traz Antonio Candido em destaque na capa, dedicandoIhe metade do volume com a reprodução de alguns dos textos presentes no livro em homenagem aos seus sessenta anos, Esboço de figura, e republicando também "A verdade sobre a repressão", que Candido publicara no Opinião em janeiro de 1973. A Reunião Anual da SBPC, novamente, é destaque de capa no número 14 (out./nov. 1979), que tem como primeiro artigo a comunicação feita por Celso Furtado na sessão inaugural do evento. 0 número 15 , porém, seria lançado apenas em setembro de 1980 . Sutilmente, a revista deixa de ser uma "revista cultural brasileira publicada mensalmente" - periodicidade poucas vezes cumprida, afinal - para ser apenas uma "revista cultural brasileira". A periodização abaixo do número informa: Dezembro 79/Agosto 80 . Seria o último número.

\title{
O “novo" intelectual
}

Em 1968 a ditadura promove a grande reforma do ensino superior brasileiro. Entre as principais mudanças introduzidas estavam a criação da carreira acadêmica/universitária (em substituição à cátedra vitalícia) e a implementação de um sistema de pós-graduação no país. 
Menos de dez anos depois, em setembro de 1977, Almino Afonso, que retornara do exílio um ano antes, em entrevista ao jornal Versus, discorre sobre a participação dos intelectuais no debate político do período. Ao refletir sobre a contribuição do intelectual, o ex-ministro de Jango destaca o surgimento, a partir de meados da década de 1970, de um "novo estilo de comportamento acadêmico", propiciado pela carreira universitária e a crescente realização de pesquisas em nível de pós-graduação. Esse novo estilo, diz Almino, contrasta com o período anterior ao golpe, "quando predominavam, entre nós, trabalhos de caráter ensaísta" (AFONSO, 1977, p. 15). ${ }^{14} \mathrm{E}$, pelas particularidades do campo, isto é, tendo em vista seus objetos de estudo, não é surpresa que, na "crista da onda" - tanto na universidade quanto no debate político - estivessem os cientistas sociais.

\begin{abstract}
Nos dois últimos anos, em especial, cresce uma outra forma de manifestação intelectual. Parece claro que, na crista da onda, estão os cientistas sociais. Através de conferências, seminários, de publicação de ensaios ou de resultados de pesquisa, o cientista social passou a analisar, criticamente, o processo social e político. Em outras oportunidades, numa sociedade aberta onde a ação política fosse assegurada a todos, essa crítica talvez não ultrapassasse o âmbito da ciência, ou talvez, quando muito, influísse indiretamente no processo político. Hoje, porém, ela ganha uma ressonância política autônoma (AFONSO, 1977, p. 13).
\end{abstract}

De fato, é significativo o desenvolvimento das Ciências Sociais na década de 1970, o que pode ser medido, segundo Maria Hermínia Tavares de Almeida, "tanto pela vigorosa construção institucional, cristalizada no surgimento e/ou consolidação dos programas de pós-graduação e dos centros privados de pesquisa, quanto pelo volume e qualidade da produção acadêmica" (ALMEIDA, 1992, p. 28). ${ }^{15}$ Sobre o processo de consolidação do campo disciplinar das Ciências Sociais no Brasil, ainda, vale destacar, conforme Sergio Miceli, que,

enquanto em São Paulo [na Escola de Sociologia e Política e na Universidade de São Paulo] os cientistas sociais se tornam cada vez mais profissionais acadêmicos, metidos de roupa e tudo na construção da corporação em cujo êxito eles eram os maiores interessados e os primeiros beneficiários, os praticantes das Ciências Sociais cariocas são, em sua maioria, e com as exceções conhecidas, membros por inteiro das elites políticas e culturais (MUCELI, 1989, p. 87).

14 Sobre os trabalhos de "caráter ensaísta", segue Almino (1977, p. 15): "muitos deles [eram] realmente criadores e brilhantes. Mas, onde ficava o diagnóstico de nossa realidade social? Onde pesquisas sobre a estrutura da classe operária no Brasil? [...] Um sem número, enfim, de problemas que devem ser objetos de estudos científicos, constituindo uma contribuição especificamente intelectual, porém já norteada por uma preocupação política. Uma atividade assim permitiria colher dois resultados, cada qual o mais importante: apoio a uma programação política realmente fundada na realidade; base para um conhecimento científico da sociedade brasileira, mais profundo e mais abrangente". Não podemos esquecer que, durante o período chileno de seu exílio, Almino Afonso lecionou na Universidade Católica (1972-1973) e foi diretor da Faculdade Latino-Americana de Ciências Sociais (FLACSO) (1973-1974).

${ }^{15} \mathrm{~A}$ autora, lembremos, foi a secretária de redação de Argumento. 
Não é por acaso, pois, que, dentre os novos intelectuais, estivessem na "crista da onda" os cientistas sociais agrupados no Centro Brasileiro de Análise e Planejamento (CEBRAP). Fundado em 1969, com aporte financeiro da Fundação Ford, o CEBRAP reuniu professores e pesquisadores ligados, em sua maioria, à USP, alguns deles afastados compulsoriamente da universidade após o Al-5. ${ }^{16}$

Ao longo de toda a década, mas particularmente na sua primeira metade, o CEBRAP foi um polo dinamizador e ponto de referência para a vida acadêmica brasileira no domínio das Ciências Sociais. Esse papel deveu-se à sua produção interna, mas também à sua capacidade de acolher e organizar o debate de ideias fermentadas em outros centros nacionais (ALMEIDA, 1992, p. 28).

Analisando a participação do grupo no Opinião, Almeida destaca que ele foi responsável por 55 dos 121 artigos de cientistas sociais publicados no semanário. ${ }^{17} \mathrm{~A}$ esse grupo, ainda, "foram se somando cientistas sociais já conhecidos ou em começo de carreira nas universidades paulistas - especialmente USP e Unicamp -, pertencentes ao círculo de influência" do centro. "Pelo menos para o grupo do CEBRAP - segue a autora - a colaboração no semanário foi uma via de ingresso na política, não só devido ao prestígio público que ganharam, como pela ponte que por aí estabeleceram com o MDB" (ALMEIDA, 1992, p. 25-26). ${ }^{18}$ É preciso atentar para o prestígio público proporcionado por essa colaboração (assim como em Argumento e nos Ensaios/Cadernos), pois, enquanto pesquisadores, já contavam com duas revistas do próprio centro desde 1971: Cadernos CEBRAP e Estudos CEBRAP. ${ }^{19}$

Mas os cebrapianos não apenas colaboravam com o semanário. Segundo Paulo Markun, além do conselho de colaboradores - que não se reunia, servindo mais como uma lista de notáveis -, foi criado também, após a saída da primeira equipe de redação em março de 1975, uma espécie de conselho editorial informal, composto por Gasparian e membros do CEBRAP, que se reunia regularmente uma vez por semana ou a cada quinze dias em São Paulo para discutir as tendências e linhas a serem adotadas (KENSKI, 1990, p. 57).

\footnotetext{
${ }^{16}$ Foram afastados da USP Fernando Henrique Cardoso, José Arthur Giannotti, Elza Berquó e Paul Singer. Chico de Oliveira, que entra para o centro em 1970, havia trabalhado com Celso Furtado na Superintendência do Desenvolvimento do Nordeste (SUDENE) e não tinha ligação com a USP ou outra universidade.

${ }^{17}$ Almeida inclui sob essa classificação não apenas os cientistas sociais stricto sensu, mas, também, os economistas, historiadores, filósofos etc. Paul Singer (19 artigos), Fernando Henrique (12) e Chico Oliveira (11) são os três maiores colaboradores do grupo.

${ }^{18}$ A colaboração no Opinião (e na Argumento e nos Cadernos, adicionamos) leva ao grupo o prestígio público, pois, enquanto pesquisadores, já contavam com duas revistas do próprio centro desde 1971: Cadernos CEBRAP e Estudos CEBRAP.

${ }^{19}$ Tonico Ferreira, secretário de redação de Opinião até março de 1975, lembra: "nós, jornalistas, aconselhávamos os intelectuais a escreverem de forma mais acessível. O Fernando Henrique, algumas vezes, tomou esse conselho muito ao pé da letra e tentava ser popular usando expressões como 'é aí que a porca torce o rabo'. Os primeiros textos dele acabaram sendo aprimorados na redação e acho que isso ajudou ele a escrever melhor". (SEMANÁRIO LANCOU FHC, 1997, p. 16)
} 
A presença direta do CEBRAP em Argumento, que teve apenas quatro números, por sua vez, se restringe a um artigo de José Arthur Giannotti, um de Roberto Schwarz e outro de Fernando Henrique Cardoso (que estaria presente também no número 5 , conforme a contracapa do último número). Por outro lado, dos cerca de 67 nomes que encontramos na revista, 32 eram ligados à USP/Unicamp. Nos Cadernos/Ensaios, que tem em Fernando Henrique o nome mais constante (sete artigos e um debate com Celso Furtado), dos 106 colaboradores brasileiros, 44 tinham essa ligação com as universidades paulistas. ${ }^{20}$

As contribuições dos cientistas sociais se dedicam, sobretudo, a duas questões principais: na economia, o modelo de desenvolvimento econômico; na política, o retorno da democracia. A concordância entre eles nem sempre é pacífica ${ }^{21}$, e o mesmo pode ser dito com relação ao proprietário das publicações. Conforme Maicon Carrijo:

\begin{abstract}
Com esses contatos, alguns que vinham de longa data e muitos próximos, nem sempre existia uma afinidade completa. O caso de Fernando Henrique Cardoso, que pode ser desdobrado para outros membros do CEBRAP, é novamente exemplar. Em 1973, mesmo ano do lançamento do livro de Gasparian editado pela Civilização Brasileira [Capital estrangeiro e desenvolvimento da América Latina], o sociólogo publicou no jornal Opinião um importante artigo intitulado "Os mitos da oposição", dividido em duas partes. Nele, curiosamente, sintetizou sua crítica aos princípios do nacional-desenvolvimentismo - as falsas crenças da esquerda, de acordo com sua análise -, colocando-se do lado oposto do que foi apresentado em algumas passagens pelo amigo dono do jornal no livro que acabara de ser lançado. (CARRIJO, 2013, p. 107)
\end{abstract}

Com relação ainda às discordâncias, essas indicam a razão pela qual Fernando Gasparian mantém Celso Furtado entre seus principais colaboradores. Não pertencendo a nenhuma das linhas apontadas por Belluco, o economista está presente no conselho de redação de Argumento e no conselho de colaboradores de Opinião, e contribui em todas as publicações. São cinco artigos em Opinião, dois em Argumento e outros quatro nos Cadernos/Ensaios (além do debate com Fernando Henrique no lançamento da revista).

Mas se os critérios da pesquisa científica passam a pautar os estudos sociais e as humanidades ${ }^{22}$, também é verdade que, nesse mesmo período, há uma crescente

${ }^{20}$ Aos quais podemos somar Peter Fry, Gerard Lébrun e, pela ligação com Antonio Candido, Ángel Rama e Marta Traba, colaboradores também de Argumento. Os outros membros nucleares do CEBRAP que escrevem nos Cadernos são Schwarz (4 artigos), Giannotti ( 3 artigos), Chico de Oliveira (2) e Ruth Cardoso (2). Cf. Base de dados Periodismo Literário e Cultural, NELIC, UFSC.

${ }^{21}$ Para uma leitura desses textos, ver BELLUCO (2015). Belluco aponta três grandes linhas de pensamento e atuação: a autonomista (Francisco Weffort e José Álvaro Moisés), a marxista (Chico de Oliveira e Florestan Fernandes) e a liberal (Fernando Henrique e José Arthur Giannotti). Weffort e Moisés deixariam o CEBRAP para, juntos, fundarem em 1976 o Centro de Estudos de Cultura Contemporânea (CEDEC).

${ }^{22}$ Sem deixar de fora a literatura: vide a polêmica em torno da teoria literária na segunda metade da década, ou, melhor, a polêmica em torno do estruturalismo enquanto teoria aplicada ao estudo da literatura. Registre-se também que, ao passo que a sociologia se distancia da literatura, substituindo o ensaio pelo artigo, o jornalismo vai na mão contrária, reivindicando alguma literatura em seu fazer 
politização das reuniões da SBPC, que passam a contar, a partir justamente do início dos anos 1970, com a presença também das "ciências" sociais e humanas, incluindo aí os estudos literários. Como destaca Almeida (1992, p. 21) "de evento de importância científica transformaram-se em foro nacional de debate dos grandes temas da política nacional, logrando uma projeção para além dos circuitos estritamente científicos e acadêmicos". Opinião e Cadernos/Ensaios dão ampla repercussão aos congressos da SBPC, reproduzindo uma série de comunicações apresentadas no evento, inclusive algumas sobre literatura.

Ao final da década, os intelectuais acadêmicos e as discussões no campo da ciência brasileira de modo geral contariam já com seu espaço público garantido: “a partir da experiência de Opinião a participação de intelectuais acadêmicos na imprensa tornou-se comum e reproduziu-se em veículos de circulação mais ampla, tão logo a censura prévia foi levantada" (ALMEIDA, 1992, p. 38).

\section{Passagem e homenagem}

Com um editorial em tom de manifesto, Argumento colocava-se como uma forma de preenchimento crítico do "vácuo cultural" - ou "vazio cultural", como a questão ficou mais conhecida $^{23}$ - que teria se abatido sobre o país. Em julho de 1971, em resposta a um questionário da revista Visão, elaborado com o objetivo de fazer o balanço cultural de 1970, artistas e intelectuais constatavam que um perigoso "vazio cultural" estava se instalando no país. Entre os motivos apontados como responsáveis pela pouca produção, dois se destacavam: Al-5 e censura. Zuenir Ventura, porém, ao comentar as respostas, pergunta: “o Al-5 e a censura teriam sido os únicos responsáveis pelo impasse em que se encontra a cultura brasileira?" Embora não discorde, vai além:

Envolvidos no desespero de uma luta perdida em que estão em jogo a sua dignidade e a sua sobrevivência, os intelectuais brasileiros nem sempre tiveram lucidez para perceber que, independentemente do Al-5, a cultura vive uma fase de transição [...]. Quase sempre sem levar em consideração que nos últimos sete anos - Brasil se afirmou através da franca adoção do modelo capitalista de desenvolvimento e que esse modelo determina formas peculiares de cultura (VENTURA, 2000, p. 47).

Em agosto de 1973 - poucas semanas antes da estreia de Argumento, portanto -, na mesma revista Visão, Zuenir retoma o assunto, dessa vez apontando que o "vazio cultural" estaria sendo preenchido de três maneiras: por uma cultura explicitamente crítica, por uma contracultura que buscava dentro do próprio consumo novas formas de expressão, mas,

com o jornalismo literário (new journalism) em voga nesse mesmo período, notadamente com os ditos romances-reportagem. Para um apanhado sobre essas discussões, ver, entre outros, SÜSSEKIND (2004).

${ }^{23} \mathrm{E}$ como constava também na primeira redação do manuscrito, conforme Pedro P. Pinto (2013, p. 142-148). 
principalmente, por uma cultura comercial, de simples entretenimento (VENTURA, 2000, p. 60).

Buscando preencher o vácuo com o que houvesse de "vivo, válido e independente" na circunstância cultural brasileira de então, em oposição à acomodação, ao arrivismo e, destacamos, à dependência, os intelectuais de Argumento parecem, pois, já ter adquirido uma "consciência amena" acerca da consolidação da indústria cultural no país. Ao mesmo tempo, não nutrem ilusões: se o Al-5 e a censura não explicam de todo o panorama, muito contribuem para o quadro. Assim como Opinião um ano antes, Argumento surge num momento bastante autoritário da ditadura. Obstáculos e restrições, portanto, são esperados, e serão mesmo indicativos do sucesso da revista, que, ante a arbitrariedade e o consumo fácil, se propõe como um esforço de lucidez (vide Zuenir), destacando o papel iluminista a ser cumprido pela intelectualidade, portadora privilegiada do argumento. ${ }^{24}$

Esse esforço de lucidez se traduz na revista notadamente na forma do ensaio, que responde por metade dos artigos publicados. E se faz também notadamente a partir da literatura ou do campo cultural (isto é, cinema, teatro, artes plásticas, etc.), que respondem por metade dos ensaios, com a economia, a política e a sociologia, juntas, respondendo, grosso modo, pelos demais. Publicadas nas últimas páginas, as resenhas formam o segundo grande corpo de textos da revista. Foram 23 em apenas quatro números, novamente com destaque para o campo literário e cultural. ${ }^{25}$

Que questões culturais ocupem a maior parte de uma "revista mensal de cultura" parece-nos evidente. Não podemos nos esquecer, no entanto, do caráter francamente político de Argumento. Dessa perspectiva, podemos dizer que a revista filia-se - ainda - à tradição que não só vê o intelectual como o portador do argumento, como também o ensaio como a forma privilegiada de expressão e a cultura como o lugar privilegiado de enunciação acerca do estado de uma dada sociedade. Já em seu primeiro número Argumento publicava dois ensaios que se tornariam "clássicos": "Literatura e subdesenvolvimento", de Antonio Candido, e "Cinema: trajetória no subdesenvolvimento", de Paulo Emílio Sales Gomes.

Contra os fatos, no entanto, não eram permitidos argumentos. Anos depois, num texto em homenagem a Antonio Candido, Fernando Henrique Cardoso lembraria: "Contra fatos (isto é, arbitrariedades), dizia o slogan da revista, há argumentos. O iluminismo que pregávamos foi, naturalmente, apagado pela estupidez da censura" (CARDOSO, 1992, p. 39, grifo nosso).

Uma nova tentativa de "iluminismo" - mais "fosca", é preciso reconhecer - surgiria com os Cadernos de Opinião. Se a revista é pouco lembrada, ao contrário da irmã mais velha e famosa, isso talvez se deva ao seu caráter híbrido, ou, aventamos a hipótese, seu caráter de passagem. Com a publicação, de um lado, de ensaios de maior fôlego (como Argumento) e, de outro, artigos, resenhas e entrevistas sobre temas contemporâneos, ou da ordem do dia (como Opinião), os Cadernos buscam uma espécie de "síntese" entre a revista cultural de

\footnotetext{
${ }^{24}$ Para uma leitura mais demorada do editorial de apresentação da revista, ver CAMARGO (1998, p. 169-175).

${ }^{25}$ Para o levantamento detalhado dos textos, bem como uma leitura da revista, ver COTA (2001).
} 
ensaios e o melhor do semanário, vale dizer, entre o ensaio interpretativo, de fôlego mais abrangente, e a pesquisa universitária, mais focada.

Se Argumento era escrita basicamente por intelectuais brasileiros, os Cadernos fazem amplo uso dos acordos que Gasparian estabelecera com jornais e revistas americanas e europeias em torno de Opinião, além de republicarem textos já saídos em outras revistas latino-americanas. As traduções correspondem à metade dos textos publicados nos dois primeiros números. Há ainda a recuperação de textos de décadas anteriores e trechos de livros recentes ou a serem lançados.

A observação dos Cadernos em seu conjunto nos permite traçar, ainda, outras características da revista. A primeira delas diz respeito aos dois primeiros números: vistos em série a partir de Argumento, eles apontam para uma continuidade entre as publicações. Tal como em Argumento, predominam aqui os textos "culturais". Encontramos, além disso, por exemplo, no primeiro número dos Cadernos, o ensaio de Roberto Schwarz já publicado em Argumento n. 4 (“Criando o romance brasileiro") e, no segundo número, contribuições de Ángel Rama e Marta Traba que, tudo indica, destinavam-se à publicação em Argumento.

O terceiro número dos Cadernos (ou, melhor, o primeiro dos Ensaios), contudo, estabelece uma quebra nessa continuidade - e, também, marca a "independência" editorial de Gasparian: o amplo (e benevolente) dossiê sobre a era Vargas - que reproduz, inclusive, alguns dos discursos de Getúlio - não caberia, sabemos, em Argumento, uma revista feita e afeita à intelectualidade paulista, que tem na rejeição à herança varguista um ponto de honra. ${ }^{26}$

O quarto número, único lançado em 1977, retoma a linha editorial inicial. A partir do quinto número, porém, os Cadernos/Ensaios vão se caracterizando cada vez menos como uma revista de cultura, passando a predominar em suas páginas os textos de sociologia, política e economia. A revista também adota, de modo crescente e em termos gerais, um paradigma textual mais próximo ao "científico", ou, "universitário": além de acompanhar de perto as reuniões anuais da SBPC, trazendo em suas páginas comunicações ali apresentadas, os Cadernos/Ensaios publicam uma grande quantidade de artigos (não apenas de sociologia, economia ou política) cujas tabelas, vocabulários e notas de rodapé não deixam dúvida acerca de sua origem acadêmica. Aqui, nos parece, não podemos negligenciar a participação de Dalva Gasparian na revista, primeiro como coeditora, depois como secretária da redação: em 1975 Dalva entra para o curso de Ciências Sociais da PUC-Rio.

Entre os colaboradores, aqueles ligados ao CEBRAP e/ou USP e Unicamp são presença constante. Essa presença e ascendência acentuada da universidade paulista nos Cadernos/Ensaios não significa o abandono, por parte de Gasparian, de seu ideário nacionaldesenvolvimentista. Se sua avaliação da era Vargas marca o primeiro termo do binômio, é sua apreciação pelo pensamento de Celso Furtado o que marca o segundo. Furtado, já destacamos, é presença constante em todas as publicações de Gasparian.

A discussão sobre a literatura (ou a cultura, de modo geral) na revista tem como característica principal a presença majoritária de textos "culturais" traduzidos,

\footnotetext{
${ }^{26}$ É no período Vargas, lembremos, que a família Gasparian inicia sua atividade industrial.
} 
particularmente da Le Nouvel Observateur e da New York Review of Books. Há que se levar em consideração o surgimento, nesse mesmo período, de revistas de fato culturais ou ao menos mais restritas ao campo (Almanaque, José, Escrita, etc.). Também chama atenção a presença de distintas orientações críticas (ou a impossibilidade de uma frente única "cultural") - Roberto Schwarz, Walnice N. Galvão, Luiz Costa Lima, Silviano Santigo, Antonio Callado -, bem como as distintas origens destas colaborações: as de Schwarz já haviam sido publicados ou estavam sendo lançadas em livro; a de Walnice e as de Costa Lima eram, tudo indica, inéditas quando publicadas na revista; as de Silviano foram apresentadas nas reuniões da SBPC de 1978 e 1979; um dos textos de Callado foi apresentado como conferência na Universidade de Cambridge em 1974 e outro apresentado na mesa dividida com Silviano na SBPC de 1978.

De todas as características, contudo, a mais marcante (embora sutil), sem dúvida, é aquela que marca uma passagem. Vimos que os principais nomes aí presentes repetem aqueles das demais iniciativas de Fernando Gasparian, isto é, o jornal Opinião e a revista Argumento. À exceção de Celso Furtado, esses nomes estão ligados, fundamentalmente, a dois grupos: o grupo Clima, que se constituiu em torno da revista de mesmo nome, publicada entre 1941-1944, como Antonio Candido e Paulo Emílio Sales Gomes; e outro, mais novo, que se constituiu através do CEBRAP, fundado em 1969, como Fernando Henrique Cardoso, José A. Giannotti e Roberto Schwarz.

A leitura dos Ensaios/Cadernos nos aponta uma inversão de posição entre esses nomes. Se aqueles de Clima eram proeminentes em Argumento, nos Cadernos essa posição é ocupada pelos nomes ligados ao CEBRAP. É certo que a mudança de posições está ligada, também, aos perfis das revistas. Argumento era uma revista cultural com espaço para sociologia, economia e política, um perfil que tem continuidade nos dois primeiros números dos Cadernos. A partir do número 5 os Cadernos invertem essa hierarquia, ainda que passe a se chamar, oficialmente, uma "revista cultural brasileira" a partir do número 12.

Essa mudança de posições se deve, notadamente, à formação e emergência de uma nova intelectualidade, especializada desde a graduação, cujos escritos e ideias, como dizia Almino Afonso, têm suporte na pesquisa desenvolvida na universidade ou em centros de pesquisa. Resta clara a perda da relevância política das questões culturais no período, vale dizer, a cultura, de modo geral, deixa de ser um locus intelectual relevante para se pensar os problemas do país e sua saída da ditadura. Uma mudança, portanto, no/do próprio trabalho intelectual. E que foi adiada, em certa medida, no Brasil, pela ditadura.

Basta lembrar alguns nomes, até bem pouco tempo limitados, em sua significação, à vida universitária, que hoje são figuras nacionais, requisitados pelos jornalistas, citados a cada instante, como Fernando Henrique Cardoso, Francisco Weffort, Paul Singer, Chico Oliveira, Maria da Conceição Tavares, José Arthur Giannotti, e tantos outros que transcendem os limites do campo acadêmico (AFONSO, 1977, p. 13).

Clima (a revista e o grupo) e CEBRAP têm como ponto em comum, de partida ou chegada, a Universidade de São Paulo. Os Cadernos/Ensaios cumprem, pois, um ritual de 
passagem: o peso intelectual do primeiro grupo é herdado pelo segundo, que assume o protagonismo. Ao primeiro, sintomaticamente, cabe o lugar da homenagem: a Paulo Emilio, morto em 1977, no número 6 (jun. 1978), e a Antonio Candido, pelo seu aniversário de 60 anos, no número 13 (ago./set. 1979).

A dinâmica do tempo que se abre - a abertura lenta e gradual da ditadura - impõe a mudança: há que se contrapor de modo mais "prático" ao regime, e os "novos" intelectuais são os mais bem aparelhados para os debates. Não por acaso, assim que possível, grande parte deles vai migrar para a política, ocupando, a seguir, cargos-chave na administração pública e, mais ainda, tornando-se mesmo legisladores, para surpresa de seus mestres, os intérpretes. A bem dizer, com Julien Benda, que muitos deles trairiam sua função em proveito, justamente, de interesses práticos.

Os Cadernos de Opinião seriam encerrados com um número cuja periodização - dez. 1979/ago. 1980 - já indicava sua saída de cena. Coincidentemente, em sua edição de 8 de outubro de 1980, Veja trazia uma matéria sobre o "surto" de revistas culturais verificado a partir do final da década de 1970 (O DEBATE EM REVISTA, 1980, p. 81-82). Com o fim da censura prévia e ocupando o espaço aberto pela partidarização veloz da imprensa alternativa, diz a reportagem, surgiram revistas de baixa tiragem, feitas por pouca gente e cujo êxito editorial não se media mais exclusivamente por seu sucesso entre o público universitário, mas também por sua capacidade de suscitar temas ou polêmicas. Dos exemplos mencionados destaca Oitenta, Almanaque e Rádice, além da Encontros com a Civilização Brasileira, uma das tiragens recordes (20 mil exemplares), mas, neste último caso, para apontar seu descompasso: "ainda a tribuna de algumas nobiliárquicas figuras da intelligentzia nacional [...], com uma linguagem tão vetusta quanto seus temas [...], a Civilização, querendo ocupar o espaço deixado por si mesma, ocupou um espaço que foi corroído pela década" (O DEBATE EM REVISTA, 1980, p. 82). ${ }^{27}$ Analisando mais detidamente a questão, diz o autor:

Entre as lições do recente surto de revistas culturais - resumido em mais títulos,

\footnotetext{
${ }^{27}$ As demais revistas citadas, nem todas culturais, são Temas, Contraponto, Religião e Sociedade, Revista Brasileira de Economia, Conjuntura Econômica, Revista de Economia Política, Polímica e Arte em Revista. Das destacadas pela reportagem, porém, apenas Oitenta surgira em 1979. Almanaque e Rádice surgiram em 1976, correndo, portanto, principalmente a segunda, o risco de serem censuradas previamente. Encontros com a Civilização Brasileira, por sua vez, foi lançada em julho de 1978, um mês depois apenas de retirada a censura prévia dos últimos jornais, e talvez por isso mesmo tenha adotado uma estratégia já nossa conhecida: como explica seu diretor-responsável Ênio Silveira na apresentação do número 1 , ou, melhor, do "volume 1", a revista não é uma revista, mas uma "coleção de livros" - como registra devidamente sua ficha catalográfica, tal qual à dos Ensaios de Opinião. É preciso lembrar que a emenda constitucional aprovada pelo Congresso em outubro de 1978 - que revogava todos os Atos Institucionais - tem validade somente a partir de 10 de janeiro de 1979 e, também, que a nova Lei de Segurança Nacional sancionada em dezembro de 1978 continuava tipificando o crime de "propaganda subversiva". Ainda sobre os destaques da reportagem, Rádice era a única revista realmente alternativa, sem apoio editorial. Almanaque era publicada pela Brasiliense, Encontros pela Civilização Brasileira e Oitenta pela L\&PM.
} 
especialização e tiragens menores - uma delas é abalar o mito de que, uma vez fechada a negra cortina dos anos de intensa repressão, o país se iluminaria com súbita prodigalidade. [...] De qualquer forma, hoje, ao contrário de há cinco ou seis anos, quando as fatias do bolo cultural eram distribuídas entre menos parceiros, não bastam figuras ilustres e amplas frentes intelectuais para levar avante um projeto (O DEBATE EM REVISTA, 1980, p. 82).

E cita, em seguida:

'Antigamente, muita gente comprava uma publicação como forma de protesto, mas hoje a compra é mais racional, menos emocional', diz Fernando Gasparian, um veterano no assunto, responsável pelos Cadernos de Opinião e pela extinta Argumento.

\section{Referências}

AFONSO, Almino. O intelectual e a política. Versus, São Paulo, n. 14, p. 12-16, set. 1977.

ALMEIDA, Maria Hermínia Tavares de. Tomando partido, formando opinião. Cientistas sociais, imprensa e política. São Paulo: Sumaré, 1992.

BELLUCO, Hugo A. de Lemos. Ciências Sociais e pensamento político. O grupo da USP e a frente democrática a partir dos seminários Opinião e Movimento (1972-1981). Tese (Doutorado em História). Instituto de Ciências Humanas e Filosofia, Universidade Federal Fluminense, Niterói, 2015.

CADERNOS DE OPINIÃO É APREENDIDO. Jornal do Brasil, Rio de Janeiro, 7 ago. 1975, p. 7.

CAMARGO, Maria Lucia de Barros. Resistir: quem há de? In: ANTELO, Raul et al. Declínio da arte, ascensão da cultura. Florianópolis: Letras Contemporâneas/ABRALIC, 1998, p. 169-175.

CANDIDO, Antonio. Depoimento. 80FHC, 2011. Disponível em www.fhc80anos.com.br. Acesso em: 12 fev. 2017.

CANDIDO, Antonio. Contra fato, haverá argumento? Argumento, Rio de Janeiro, n. 2, p. 3, dez. 2003.

CANDIDO, Jeferson. Para além da frente ampla: Fernando Gasparian e a educação das elites. Tese (Doutorado em Literatura). Centro de Comunicação e Expressão, Universidade Federal de Santa Catarina, Florianópolis, 2018.

CARDOSO, Fernando Henrique; WINTER, Brian. Jeitinho. In: O improvável presidente do Brasil. Recordações. Trad. Clóvis Marques. Rio de Janeiro: Civilização Brasileira, 2015, livro digital.

CARDOSO, Fernando Henrique. Um ex-aluno. In: D'INCAO, Maria Angela; SCARABÔTOLO, Eloísa Faria (Orgs.). Dentro do texto, dentro da vida. Ensaios sobre Antonio Candido. São Paulo: Companhia das Letras / Instituto Moreira Salles, 1992, p. 37-40.

CARRIJO, Maicon V. Silva. Cientistas sociais e historiadores no mercado editorial do Brasil. A coleção Estudos Brasileiros da editora Paz e Terra (1974-1987). Tese (Doutorado em História). 
Faculdade de Filosofia, Letras e Ciência Humanas, Universidade de São Paulo, São Paulo, 2013.

COTA, Débora. Contra fato, há Argumento. Leitura de uma revista cultural de resistência. Dissertação (Mestrado em Literatura). Centro de Comunicação e Expressão, Universidade Federal de Santa Catarina, Florianópolis, 2001.

DINES, Alberto. Andanças da censura. Folha de S. Paulo, São Paulo, 24 ago. 1975a, p. 8.

DINES, Alberto. A indefinição como tática. Folha de S. Paulo, São Paulo, 10 ago. 1975b, p. 6.

DIRETOR EXPLICA PUBLICAÇÃO. O Estado de S. Paulo, São Paulo, 20 ago. 1975, p. 6.

DOCUMENTOS DA APREENSÃO DOS CADERNOS DE OPINIÃO 2. Cadernos de Opinião, Rio de Janeiro, n. 12, jul. 1979, p. 4-5.

DPF DIZ QUE TIROU DAS BANCAS Argumento por faltar censura prévia. Jornal do Brasil, Rio de Janeiro, 17 out. 1973, p. 17.

EDITORA RECORRE AO TFR para liberar revista. Correio Braziliense, Brasília, 25 maio 1974, p. 2.

[EDITORIAL]. Cadernos de Opinião, Rio de Janeiro, n. 12, jul. 1979, p. 3.

[EDITORIAL]. Argumento, Rio de Janeiro, n. 1, out. 1973, p. 1.

FERREIRA, Jairo. Opinião volta às bancas, mas só com ensaios. Folha de S. Paulo, 6 jun. 1977. llustrada, p. 8.

GASPARIAN, Fernando. O risco de publicar. In: FREIRE, Paulo; GUIMARÃES, Sérgio. Lições de casa. Últimos diálogos sobre educação. Rio de Janeiro: Paz e Terra, 2013. Livro digital. Entrevista concedida a Sérgio Guimarães, jan. 2001 e 7 jan. 2005.

GOVERNO RECORRE A AI-5 para a censura prévia da revista Argumento. Jornal do Brasil, 14 dez. 1974, p. 7.

INQUÉRITO VAI À AUDITORIA. Folha de S. Paulo, São Paulo, 17 set. 1975, p. 4;

KENSKI, Vani Moreira. O fascínio do Opinião. Tese (Doutorado em Educação). Faculdade de Educação, Universidade Estadual de Campinas, Campinas, 1990.

KUCINSKI, Bernardo. Opinião: a frente natural. In: Jornalistas e revolucionários. Nos tempos da imprensa alternativa. 2ª ed. São Paulo: Edusp, 2003, p. 299-337.

MICELI, Sergio. Condicionantes do desenvolvimento das Ciências Sociais. In: MICELI, Sergio (Org.). História das Ciências Sociais no Brasil. Vol. 1. São Paulo: Vértice/IDESP, 1989, p. $72-$ 110.

O DEBATE EM REVISTA. Veja, São Paulo, 8 out. 1980, p. 81-82.

OS DOCUMENTOS DA CENSURA. Jornal do Brasil, Rio de Janeiro, 18 jun. 1978. Caderno especial.

PINTO, Pedro Plaza. A apresentação de Argumento. Revista da Cinemateca Brasileira, São Paulo, n. 2, jul. 2013, p. 142-148.

REJEITADA DENÚNCIA CONTRA editor de semanário carioca. O Estado de S. Paulo, São Paulo, 1 maio 1976, p. 12.

SEMANÁRIO LANÇOU FHC. Folha de S. Paulo, São Paulo, 30 mar. 1997. Brasil, p. 16.

STF ADVERTE QUE A CENSURA tem poder de exceção. Jornal do Brasil, Rio de Janeiro, 28 ago. 1975, p. 14. 
STF JULGARÁ APREENSÃO DE REVISTA. Jornal do Brasil, Rio de Janeiro, 21 ago. 1974, p. 20. STM NÃO ACHA SUBVERSÃO em conferência de D. Hélder e encerra caso contra editor. Jornal do Brasil, Rio de Janeiro, 27 jan. 1978, p. 18.

SÜSSEKIND, Flora. Literatura e vida literária. Polêmicas, diários \& retratos. 2ạ ed. Belo Horizonte: Ed. UFMG, 2004.

VASCONCELOS, Sandra. Ángel Rama no Brasil. In: VASCONCELOS, Sandra; AGUIAR, Flávio (Orgs.). Ángel Rama. Literatura e cultura na América Latina. São Paulo: Edusp, 2001, p. 33-38. VENTURA, Zuenir. Os impasses da criação. In: VENTURA, Zuenir; GASPARI, Elio; HOLLANDA, Heloisa B. de. Cultura em trânsito. Da repressão à abertura. Rio de Janeiro: Aeroplano, 2000, p. 38-85.

Recebido em: 20/10/2020

Aceito em: $23 / 11 / 2020$ 